\title{
The performance of four stroke surface ignition ceramic heater C.I. engine using ethanol-diesel blend
}

\author{
Muthuraman S. ${ }^{1}$, Rama Udaya Marthandan R. ${ }^{2}$ \\ ${ }^{1}$ Higher college of Technology, Muscat, Oman \\ ${ }^{2}$ Research scholar, Sathyabama University, India
}

Email address:

muthu9678@gmail.com (Muthuraman S.),rmarthandan@rediffmail.com (Rama U. M. R.)

\section{To cite this article:}

Muthuraman S., Rama Udaya Marthandan R.. The Performance of Four Stroke Surface Ignition Ceramic Heater C.I. Engine using Ethanol-Diesel Blend. International Journal of Energy and Power Engineering. Vol. 3, No. 2, 2014, pp. 38-45.

doi: $10.11648 /$ j.ijepe.20140302.11

\begin{abstract}
In this paper an experimental investigation on the performance of four stroke C.I. engine fueled with pure diesel (B0D100E0) and ethanol-diesel blends containing 10\%, 20\%, 25\% and 30\% by volume of ethanol (E) are evaluated. Formaldehyde (B) additive is used to solubility of ethanol in diesel that acts as a bridging agent and bonding to produce a homogeneous blend. The tests are carried out on a ceramic heater10KW single cylinder diesel engine under steady state operating conditions on two specified speeds of $1500 \mathrm{rpm}$ and 2000.rpm. The Partially Stabilized Zirconia (PSZ) ceramic heater is used to reduce the emissions from the engine and improve engine output behavior. The relevant parameters such as brake thermal efficiency (BTE), break specific fuel consumption (BSFC) and emissions are calculated for ethanol-diesel blends by B5D85E10, B5D75E20, B5D70E25and B5D65E30. The PSZ ceramic heater is used to reduce the emissions by $38 \%$ of NOx, under half load condition for the blends of B5D85E10 gives minimum CO emissions and unburned HC emissions by $7.5 \mathrm{ppm}$ from the engine and improve engine output behavior to $1.8 \%$.
\end{abstract}

Keywords: Ethanol, Formaldehyde, Emissions, Ceramic Heater

\section{Introduction}

Ethanol is an attractive alternative fuel because it is a renewable bio-based resource and it is oxygenated, thereby providing the potential to reduce particulate emissions in compression ignition engines. The diesel engine is the engine of choice for heavy-duty applications in agriculture, construction, industrial, and on-highway transport for over 50 years. Its early popularity could be attributed to its ability to use the portion of the petroleum, crude oil that had previously been considered a waste product from the refining of gasoline. Later, the diesel's durability, high torque capacity, and fuel efficiency assured its role in the most demanding applications. Diesel is one of the fuels that can be refined from crude oil. Some other refined fuels include gasoline, kerosene and heating oil. Diesel (D) fuel is considered a midweight petroleum product. Gasoline and kerosene are examples of light petroleum products. Lubricants and bunker oil are examples of heavy petroleum products. Recent engineering changes allow for the burning of more highly refined diesel fuels that pollute less [1].

The global fuel crises in the 1970s triggered awareness amongst many countries of their vulnerability to oil embargoes and shortages. Considerable attention is focused on the development of alternative fuel sources. The use of ethanol blended with diesel is a subject of research in the 1980s and it is shown that ethanol-diesel blends are technically acceptable for existing diesel engines. The relatively high cost of ethanol production at that time meant that the fuel could only be considered in cases of fuel shortages. Recently the economics have become much more favorable in the production of ethanol and it is able to compete with standard diesel. Consequently there has renewed interest in the ethanol-diesel blends with particular emphasis on emission reduction [1]. When considering an alternative fuel for use in diesel engines, a number of issues are important. These issues include supply and distribution, integrity of the fuel being delivered to the engine, emissions and engine durability. The purpose of this review is to discuss the engine performance of four stroke ceramic heater C.I engine using ethanol -diesel blends with formaldehyde additive [4].

Petroleum-based fuel is developed over many years in concert with compression-ignition (C.I.) engines and provides excellent performance in such engines. Diesel 
engines are more efficient and sturdier than spark ignition engines. However, the increase in prices of diesel fuel, reduced availability, more stringent governmental regulations on exhaust emissions and the foreseeable future depletion of world-wide petroleum reserves provide strong encouragement for the search for alternative fuels [4].

Ethanol is one of the possible fuels for diesel replacement in C.I. engines. It can be made from raw materials such as sugarcane, sorghum, corn, barley, cassava, sugar beets etc. A biomass-based renewable fuel, ethanol has cleaner burning characteristics, and a high octane rating. The application of ethanol as a supplementary compression-ignition fuel may reduce environmental pollution, strengthen agricultural economy, create job opportunities, reduce diesel fuel requirements and thus contribute in conserving a major commercial energy source [1].

\subsection{Ceramic Heater is Suited for Automobiles}

A ceramic heater [3] engine is able to operate at higher temperature enabling combustion of fuel at complete resulting to increase combustion efficiency. This should increase performance, decrease fuel consumption and reduce pollution. Ceramic Heater provides instant heat within seconds of turning, which helps save fuel and reduce emissions [6]. It is mounted through the engine head that heats up and warms air moved over its surface, and due to its inherent self-regulating characteristics. Ceramic heater for diesel combustion would represent a simple low cost and easy approach in improving diesel engine performance and fuel consumption [5].

Compatibility and bonding to produce a homogeneous blends. The blends formed spontaneously and required only minor stirring. The ethanol-diesel blends transparently indicating that the dispersion sizes are less than a quarter of a wavelength of light [7].

The process for the mixing are performed with the ethanol - diesel blends. The volume percentage are $10 \%, 20 \%, 25 \%$ and $30 \%$ of ethanol with $85 \%, 75 \%, 70 \%$ and $65 \%$ diesel and fixed 5 percentage of formaldehyde as a solvent, which are named as B5D85E10, B5D75E20, B5D70E25 and B5D65E30 [2,7].

The addition of ethanol with diesel is lowers fuel lubricity and viscosity. The variation of kinematic viscosity with percentage of ethanol present bio-based oil is effectively increase in fuel lubricity. Minimum specifications for lubricity and viscosity of ethanol-diesel blends are required in order to ensure that fuel injection system durability of diesel fuel usage and the engine is able to start reliably. Fuel viscosity also affects the atomization and injection characteristics in the combustion chamber. Lower viscosities typically result in smaller saunter mean droplets and increasing the surface area of droplets and significantly influencing the evaporation characteristics. General corrosion is caused by ionic impurities, mainly chloride ions and acetic acid [1].

The cetane number for diesel is 45 . The cetane number of ethanol is 8 . Lower cetane numbers mean longer ignition delays, allowing more time for fuel to vaporize before combustion starts. Initial burn rates are higher causing more heat release at constant volume, which is a more efficient conversion process of heat to work. It is preferable to add an ignition improver to raise the temperature of the combustion chamber by adding ceramic heater. The shielding effect of the emulsion structure delaying evaporation of the ethanol. In ceramic heater engine the ethanol molecules are free to evaporate immediately by the fuel droplets [7].

\subsection{Effect of Ceramic Heater in C.I Engine}

Heat transfer affects engine performance, efficiency, and emissions. The mass of fuel within the cylinder, higher heat transfer to the combustion chamber walls will lower the average combustion gas temperature and pressure, and reduce the work per cycle transferred to the piston. Thus specific power and efficiency are affected by the magnitude of engine heat transfer [8]. Advances in engine technology by introducing ceramic heater increases the engine output efficiency and reduce the emission parameters.

In ceramic heater C.I engine an injection pressure and rate of injection can also offset the adverse effect of ceramic heater as shown in fig: 1 . In this new system decreased in pre mixed of combustion due to decrease in ignition delay and increase the Brake Specific Fuel Consumption (BSFC).Partially Stabilized Zirconia ceramic heater is fitted inside the cylinder, because of their very high fracture toughness among ceramics, it have one of the highest maximum service temperatures $\left(2000^{\circ} \mathrm{C}\right)$ among all of the ceramic and it retain some of their mechanical strength close to their melting point $\left(2750^{\circ} \mathrm{C}\right)$. Partially Stabilized Zirconia ceramic heater is used in diesel engine because of two very notable properties, one is high temperature capability and other is low thermal conductivity. None of the other ceramics possess a thermal conductivity as low as the zirconia. This means that engine make out of zirconia would retain much of the heat generated in the combustion chamber instead of losing it to the surroundings [9].

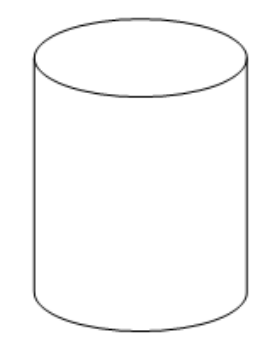

Fig 1. Ceramic heater.

\section{Experimental Work}

A different speeds stationary four stroke ceramic heater surface ignition CI engine is selected for the experiment. The major specifications of the engine are given in 
Table.1and properties of fuel used are given in table.2. The engine is connected with dynamometer, air stabilizing tank, diesel and ethanol blends consumption measuring device, exhaust gas analyzer etc. A ceramic heater is fixed inside the cylinder and connected by 12 volt DC battery to heating combustion chamber. Diesel fuel and ethanol-diesel blends with formaldehyde additive by B0D100E0, B5D85E10, $\mathrm{B} 5 \mathrm{D} 75 \mathrm{E} 20$, B5D70E25 and B5D65E30 are tested. The ethanol and additive is obtained from the local market. The engine is run on no-load condition and its speeds are adjusted to $1250 \mathrm{rpm}$ and $1500 \mathrm{rpm}$ by adjusting the screw provided with the fuel injector pump. The engine is run to gain uniform speed after which it is gradually loaded. The experiments are conducted at six power levels for each load condition. The engine is run for at least 7 minutes after which data is collected. The experiment is repeated 5 times and the average value is taken. The observations made during the test for the determination of various engine parameters Brake Specific Fuel Consumption (BSFC), Brake thermal efficiency and exhaust emissions [7].

Ethanol solubility in diesel is affected mainly by two factors, temperature and water content of the blend. At warm ambient temperatures dry ethanol blends readily with diesel fuel. Below $10^{0} \mathrm{C}$ the two fuels separate. Prevention of this separation can be accomplished in two ways: by adding an emulsifier which acts to suspend small droplets of ethanol within the diesel fuel, or by adding a co-solvent that acts as a bridging agent through molecular compatibility and bonding to produce a homogeneous blends, and the blends formed spontaneously and required only minor stirring. It also appeared as transparent indicating that the dispersion sizes were less than a quarter of a wavelength of light and were regarded as "infinitely" stable, i.e. thermodynamically stable with no separation even after several months. Blends of these surfactants with aqueous ethanol and diesel were transparent and stable at low temperatures. In ceramic heater diesel engine an injection pressure and rate can also maintain. In this system, decrease in pre mixed combustion due to decrease in ignition delay and increase the Brake Specific Fuel Consumption (BSFC) $[1,7]$.

Table 1. Tested engine specifications.

\begin{tabular}{ll}
\hline Engine type & 4-stroke single cylinder engine \\
\hline Make & Kirlosker \\
Power & $10.0 \mathrm{KW}$ \\
Bore x Stroke $(\mathrm{mm})$ & $102 \times 110$ \\
Cubic Capacity $(\mathrm{cc})$ & 898 \\
Compression ration & $18: 1$ \\
Colling system & Water cooled \\
Lubrication system & Force feed \\
Attachment & Ceramic heater(12 V,DC) \\
\hline
\end{tabular}

Table 2. Properties of blending stocks [r10].

\begin{tabular}{llll}
\hline Properties & Diesel & Ethanol & Formaldehyde \\
\hline Boiling point $\left({ }^{\circ} \mathrm{C}\right)$ & 180 & 78 & 96 \\
Flash point $\left({ }^{\circ} \mathrm{C}\right)$ & 65 & 10 & 60 \\
Density, $\mathrm{g} / \mathrm{ml}$ at $20^{\circ} \mathrm{C}$ & 0.829 & 0.789 & 1.08 \\
Oxygenate $(\mathrm{Wt} \%)$ & 0.84 & 35 & 4.75 \\
Carbonate $(\mathrm{Wt} \%)$ & - & 52 & 20 \\
Hydrogen $(\mathrm{wt} \%)$ & 87 & 13 & 38.5 \\
Viscosity, cS at $40^{\circ} \mathrm{C}$ & 13 & 1.2 & 16 \\
Cetane number & 48 & 6 & 40 \\
\hline
\end{tabular}

A dynamometer is used for measuring the power of the engine output. Exhaust gas analyzer is used for measuring the emissions of $\mathrm{CO}, \mathrm{HC}$ and $\mathrm{NOx}$ from the engine. A fuel consumption meter is used for measuring the break specific fuel consumption of the engine.

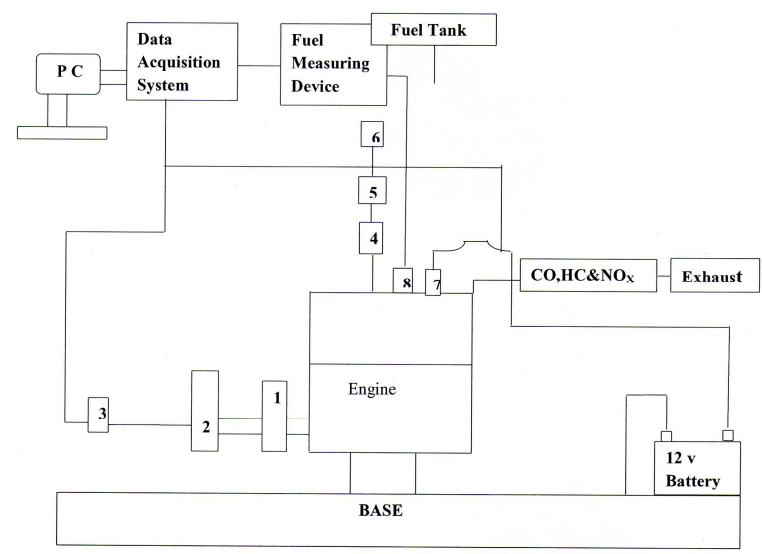

1. Flywheel

2. Dynamometer

3. R.P.M. Measuring device

4. Air stabilizing tank

5. Digital air flow meter

6. Air filter

7. Ceramic heater

8. Injector

Fig 2. Shows the experimental setup of the work.

The hot cylinder ceramic heater is accompanied by a thinner boundary layer and higher thermal gradient. As a consequence the convective heat transfer coefficient increases drastically, and overcomes the effect of the reduced temperature difference between ceramic heater and combustion chamber and reduction in the heat flux to ceramic heater. The change in performance is the introduction of ceramic heater in the cylinder that sufficiently after the combustion process. A corresponding increase in the amount of fuel burned during the diffusion phase of combustion. With heat release shifted to late in the cycle, less useful work is extracted from the ceramic heater engine. The end result is higher production of particulates which continue to burn well in to the expansion stroke. The experimental data is shows higher temperature in the ceramic heater engine. The adjustment of the injection timing is possible to partially offset the adverse effect of ceramic heater on heat release rate. The heat rejection from the ceramic heater to the combustion chamber. By 
advancing the timing the piston achieves virtually the same premixed heat release rate, but suffers even lower rates of diffusion heat release. At both timings the piston produces higher energy release later in the expansion stroke [5].

\section{Results and Discussions}

The experimental tests are carried out on the diesel engine using diesel and the blended fuels with formaldehyde on different speeds of ceramic heater diesel engine .The relevant parameters such as engine torques and fuel consumption of engine are recorded and the specific fuel consumption, Brake thermal efficiency are also calculated at $1250 \mathrm{rpm}$ and $1500 \mathrm{rpm}$. The engine emissions of $\mathrm{CO}$, unburned $\mathrm{HC}$ and $\mathrm{NOx}$ are analyzed using the exhaust gas analyzer. The results are shown as follows.

Figures shows the test results of the brake specific fuel consumptions (BSFCs) with the engine power outputs, when the engine fuelled by different blends and diesel fuel. The experiments given that the engine power could be same when fuelled by different fuel blends with some extent increases of fuel consumption. The ratio of ethanoldiesel blends gives various fuel consumption according to the percentage of ethanol present in the diesel fuel. If more ethanol is added with diesel gives more fuel consumption.

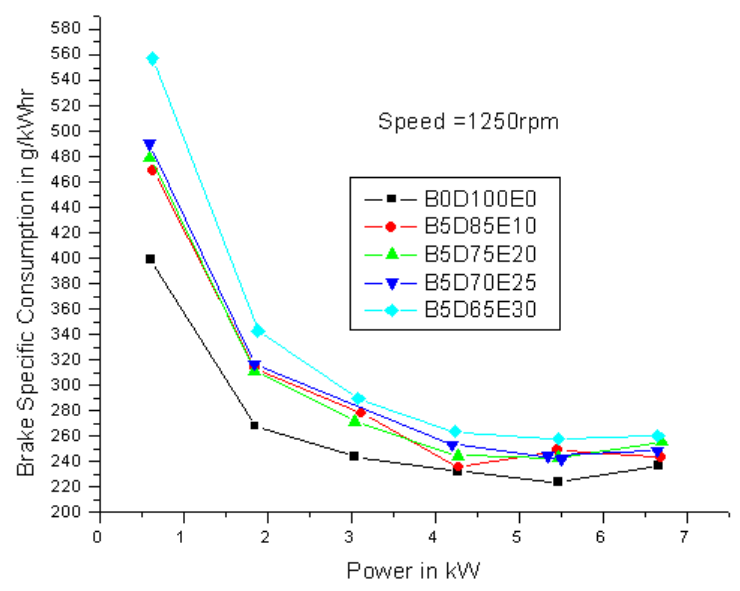

Fig 3. Brake Specific fuel Consumption of the engine for 1250rpm.

When the engine runs at $1250 \mathrm{rpm}$ on different engine loads, for the blend of B5D85E10, the BSFCs are increased by $3 \%$ for the blend of B5D75E20, the BSFCs are increased by $8 \%$ for the blend of B5D70E25, the BSFCs are increased by $18 \%$; for the blend of B5D65E30, the BSFCs are increased by $18.5 \%$. These increases of fuel consumption are due to the lower heating value of ethanol than that of pure diesel. The results show that trend of the increase of fuel consumption with the increase percentage of ethanol in the blends.

When the engine runs at $1500 \mathrm{rpm}$ on different engine loads, for the blend of B5D85E10, the BSFCs are increased by $4 \%$; for the blend of B5D75E20, the BSFCs are increased by $10 \%$; for the blend of B5D70E25, the BSFCs are increased by $12.5 \%$; for the blend of B5D65E30, the
BSFCs are increased by $15.5 \%$. These increases of fuel consumption are due to the lower heating value of ethanol than that of pure diesel. The results show that trend of the increase of fuel consumption with the increase percentage of ethanol in the blends.

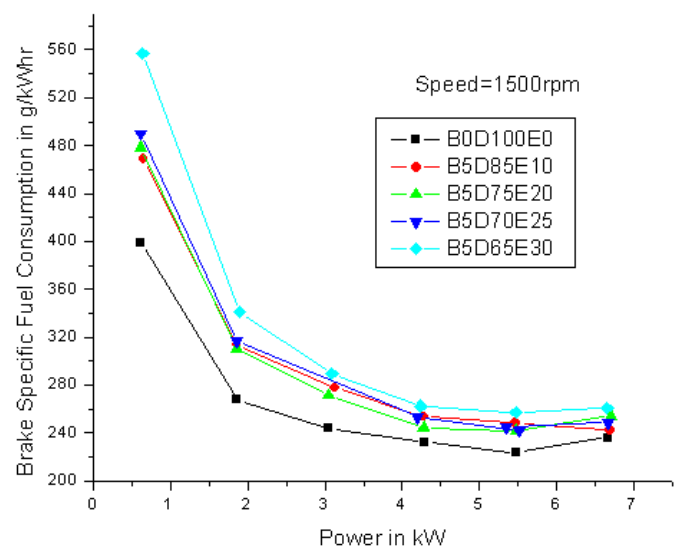

Fig 4. Brake Specific fuel Consumption of the engine for $1500 \mathrm{rpm}$.

\subsection{Results of the Brake Thermal Efficiency}

Fig: 5 shows the results of the thermal efficiencies of engine with the engine power on two tested speeds when fuelled by different fuel blends and the pure diesel. The test results show that there are some differences for the brake thermal efficiencies for different blends compared with those of diesel. When the engine run at the speed of 1250 $\mathrm{rpm}$, for the blend of B5D85E10, the thermal efficiency are decreased by $4 \%$; for the blend ofB5D75E20, the thermal efficiencies are reduced by $4.8 \%$ at the engine low loads for the blends of B5D70E25, the decreases are by $3.6 \%$ and the increases are from $0.4 \%$ to $3.5 \%$; and for B5D65E30, the decreases are by $10.8 \%$ at the low loads of the engine .The increases are by $2.2 \%$ at the high loads of the engine. These results show the differences of the thermal efficiencies between the blends and diesels are relatively small; they are comparable with each other, with some extent increases or decreases at different loads.

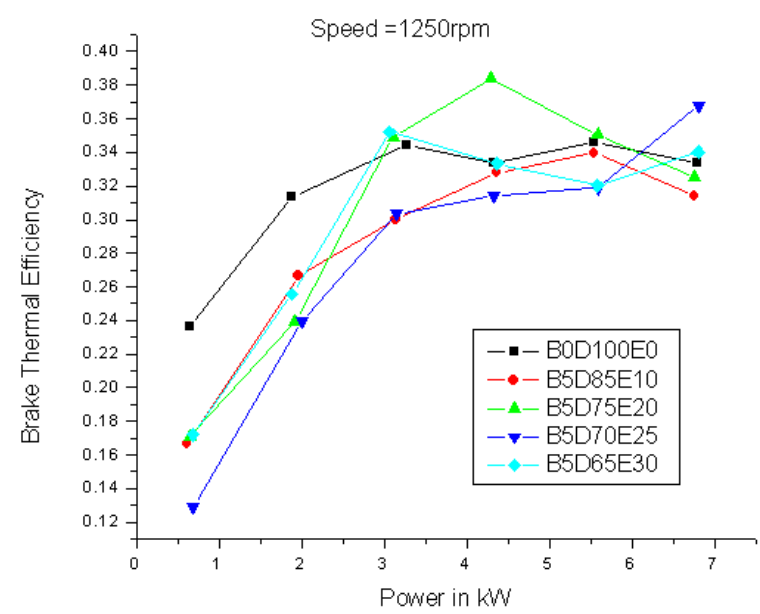

Fig 5. Brake Thermal Efficiency of the engine for $1250 \mathrm{rpm}$. 


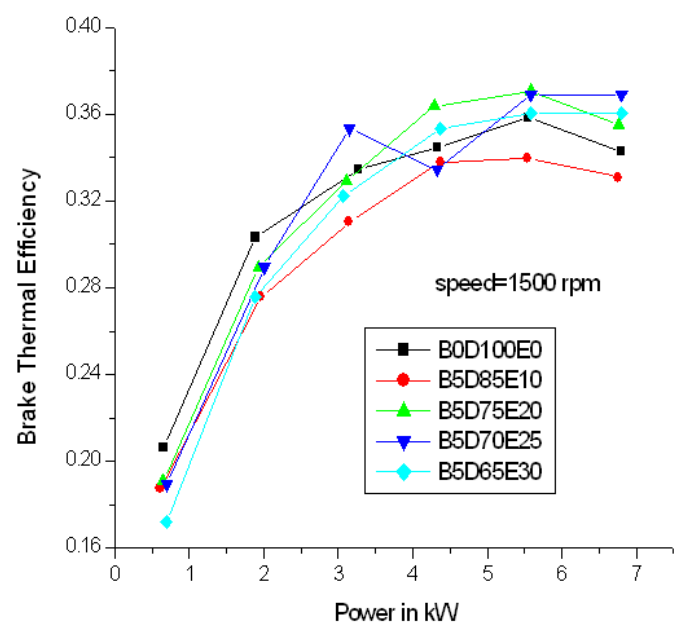

Fig 6. Brake Thermal Efficiency of the engine for $1500 \mathrm{rpm}$.

Fig6 shows the results of the thermal efficiencies of engine with the engine power on two tested speeds when fuelled by different fuel blends and the pure diesel. The test results show that there are some differences for the brake thermal efficiencies for different blends compared with those of diesel. When the engine run at the speed of 1500 rpm, for the blend of B5D85E10, the thermal efficiency are decreased by $3 \%$; for the blend ofB5D75E20, the thermal efficiencies are reduced by $5 \%$ at the engine low loads from 1.5 to $4.5 \mathrm{~kW}$, but at the high loads from 6.0 to $10 \mathrm{~kW}$ the thermal efficiencies are increased by $2.5 \%$, respectively; similar trends can be found for the blends of B5D70E25, the decreases are by $5 \%$ and the increases are by $3 \%$; and for B5D65E30, the decreases are by $12 \%$ at the low loads of the engine .The increases by $2 \%$ at the high loads of the engine. These results show the differences of the thermal efficiencies between the blends and diesels are relatively small; they are comparable with each other, with some extent increases or decreases at different loads.

\subsection{Exhaust Emissions}

The exhaust emissions are measured in terms of $\mathrm{CO}, \mathrm{HC}$, Particulates and oxides of nitrogen (Nox) emissions. The results for diesel fuel as well as ethanol-diesel blends are given below. From the figures, that the percentage of ethanol in the blends increased the percentage of $\mathrm{CO}$ emission reduced. The emission reduced by $36 \%, 56 \%, 58 \%$ and $60 \%$ with the use of $10 \%, 20 \%, 25 \%$ and $30 \%$ ethanoldiesel blends, respectively, as compared to diesel alone. This trend is due to the fact that ethanol has less carbon than diesel. Also, given the same fuel dispersion pattern as for diesel, the oxygen content of the blended fuels would help to increase the oxygen-to-fuel ratio in the fuel-rich regions. The resulting more complete combustion leads to reduce $\mathrm{CO}$ in the exhaust smoke. The NOx emissions of the engine operating on diesel and ethanol-diesel blends are also given below. It shows that as the percentage of ethanol in the blends increased, NOx emission is reduced. It reduced by $19 \%, 21 \%, 23 \%$ and $24 \%$ with the use of $10 \%$,
$20 \%, 25 \%$ and $30 \%$ ethanol-diesel blends, respectively, as compared to diesel alone. This is because the air-fuel ratio in the case of ethanol-diesel blends was lower as compared to diesel alone. Also, the latent heat of vaporization of ethanol lowers same temperature resulting in lower NOx emissions.

\subsection{Carbon Monoxide (CO) Emissions}

Carbon monoxide is a colorless and odorless but a poisonous gas. It is generated in an engine when it is operated with a fuel -rich equivalence ratio. When there is not enough oxygen to convert all carbon to $\mathrm{CO}_{2}$, some fuel does not get burned and some carbon ends up as CO. Maximum $\mathrm{CO}$ is generated when an engine runs rich. Rich mixture is required during starting or when accelerating under load. Even when the intake air - fuel mixture is lean, some $\mathrm{CO}$ is generated in the engine. Poor mixing, local rich regions, and incomplete combustion will also be the source for $\mathrm{CO}$ emissions

The fig: 7 shows the $\mathrm{CO}$ emissions from the engine at various speeds. when fuelled by different fuels. The CO emissions from the engine fuelled by the blends are higher than those fuelled by pure diesel. The higher percentages of the ethanol gives more $\mathrm{CO}$ emissions. But at the engine higher loads - which are above half of the engine load, the $\mathrm{CO}$ emissions became lower than that fuelled by diesel for all the blend fuels. At the highest engine loads tested, the reductions of $\mathrm{CO}$ emissions from the blend fuels are from $31.7 \%$ (for the blend of B5D85E10) to $43.9 \%$ (for the blend of B5D65E30). The reductions of $\mathrm{CO}$ emissions at full loads are due to the more complete combustion. The phenomenon or trend is due to that ethanol contains oxygen element in it. When the engine above its half load, the temperatures in the cylinder are high, which made the chemical reaction of fuel with oxygen be easier and the combustion became more complete.

The fig: 8 shows at $1500 \mathrm{rpm}$ when fuelled by different fuels. The $\mathrm{CO}$ emissions from the engine fuelled by the blends are higher than those fuelled by pure diesel. The higher percentages of the ethanol give more $\mathrm{CO}$ emissions. But at the engine higher loads - which are above half of the engine load, the $\mathrm{CO}$ emissions became lower than that fuelled by diesel for all the blend fuels. At the highest engine loads tested, the reductions of $\mathrm{CO}$ emissions from the blend fuels are from $32.7 \%$ (for the blend of B5D85E10) to $44.9 \%$ (for the blend of B5D65E30). The reductions of $\mathrm{CO}$ emissions at full loads are due to the more complete combustion. The phenomenon or trend is due to that ethanol contains oxygen element in it. When the engine above its half load, the temperatures in the cylinder are high, which made the chemical reaction of fuel with oxygen be easier and the combustion became more complete.

\subsection{Unburned Hydro Carbon (HC) Emissions}

Hydrocarbons, or more appropriately organic emissions, 
are the consequence of incomplete combustion of the hydrocarbon fuel. The level of unburned hydro carbons (HC) in exhaust gases is generally specified in terms of the total hydro carbon concentration expressed in parts per million carbon atoms. While total hydrocarbon emission is a useful measure of combustion inefficiency. Engine exhaust gases contain a wide variety of hydrocarbon compounds.

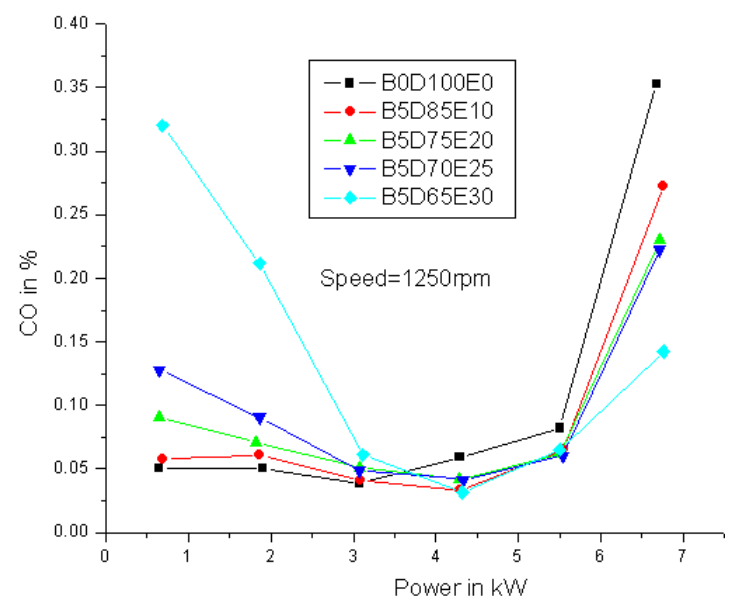

Fig 7. CO Emissions for $1250 \mathrm{rpm}$.

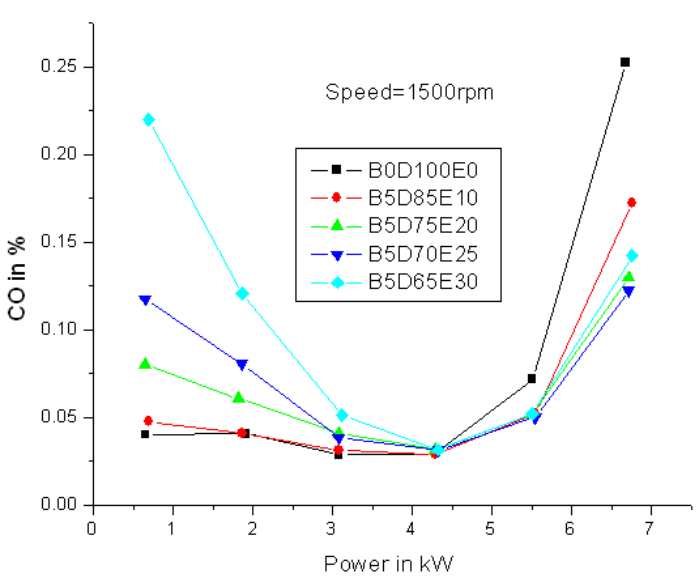

Fig 8. CO Emissions for $1500 \mathrm{rpm}$.

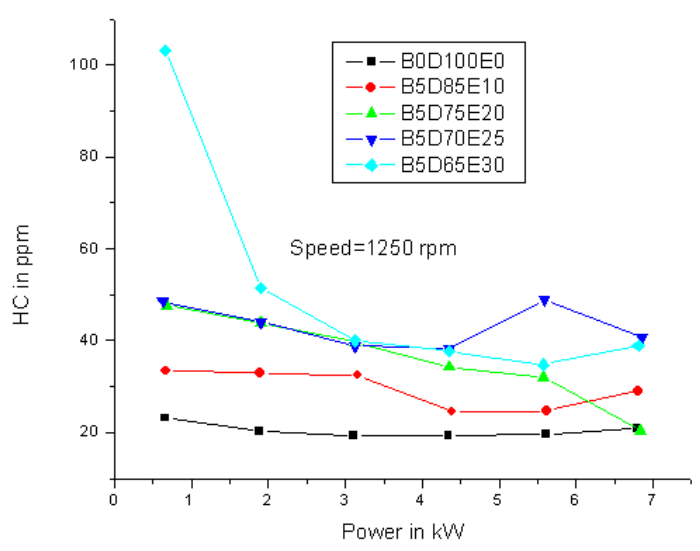

Fig 9. HC emission for $1250 \mathrm{rpm}$.

The fig: 9 shows the results of unburned $\mathrm{HC}$ emissions from the engine. The result shows that the $\mathrm{HC}$ emissions from the engine for the blend fuels are all higher when the engine run son the speed of $1250 \mathrm{rpm}$. The $\mathrm{HC}$ emissions became less as the loads increased. At this point the $\mathrm{HC}$ emissions for all blends are lower than that fuelled by pure diesel, when the engine runs at full load. The graphs shown that, $\mathrm{HC}$ emissions are reduced by $4 \%$ for the blend of $\mathrm{B} 5 \mathrm{D} 65 \mathrm{E} 30$, to $33 \%$ for the blend of B5D75E20. This is due to the high temperature in the ceramic heater engine cylinder to make the fuel be easier to react with oxygen when the engine run on the top load and high speed.

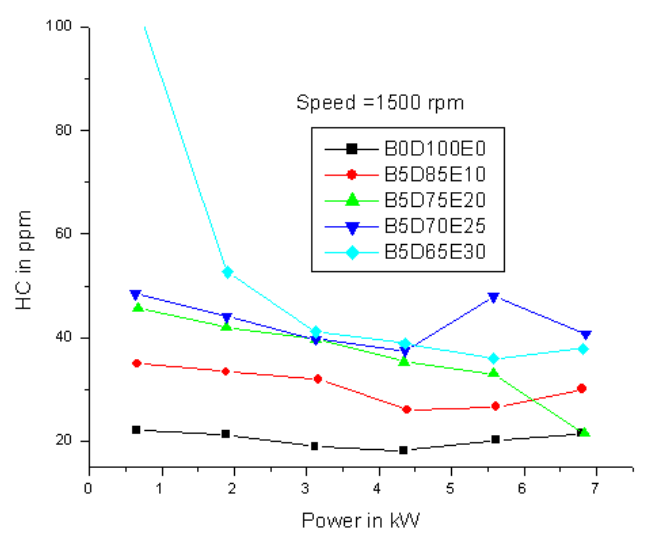

Fig 10. HC Emission for $1500 \mathrm{rpm}$.

From the results unburned $\mathrm{HC}$ emissions from the engine are shown in fig: 10. The result shows that the $\mathrm{HC}$ emissions from the engine for the blend fuels are all higher when the engine run on the speed of $1500 \mathrm{rpm}$. The HC emissions became less as the loads increased.

\subsection{Nitrogen oxides (NOx) Emissions}

The critical difference, of course, is that injection of fuel into the cylinder occurs just before combustion starts, and that non uniform burned gas temperature and composition result from this non uniform fuel distribution during combustion. The fuel air mixing and combustion processes are extremely complex. During the "premixed" or uncontrolled diesel combustion phase immediately following the ignition delay, fuel air mixture with a spread in composition about stoichiometric burns due to spontaneous ignition and flame propagation. During the mixing controlled combustion phase, the burning mixture is likely to be closer to stoichiometric. However, throughout the combustion process mixing between already burned gases, air, and lean and rich unburned fuel vapor -air mixture occurs, changing the composition of any gas elements that burned at a particular equivalence ratio. In addition to these composition changes due to mixing, temperature changes due to compression and expansion occur as the cylinder pressure rises and falls.

The test results for the NOx emissions from the engine are shown in fig: 11 when the engine ran at the speed of $1250 \mathrm{rpm}$ and above half of the engine load, the NOx emissions from the engine were higher than those of diesel when fuelled by B5D85E10. The NOx emissions from the 
engine were all lower than those of diesel when fuelled by the other blends; the reductions were between $6 \%$ and $34 \%$ for the blend of B5D75E20; the reductions were between $0.0 \%$ and $44 \%$ for the blend of $\mathrm{B} 5 \mathrm{D} 70 \mathrm{E} 25$; the reductions were between $3.5 \%$ and $75.5 \%$ for the blend of B5D65E30

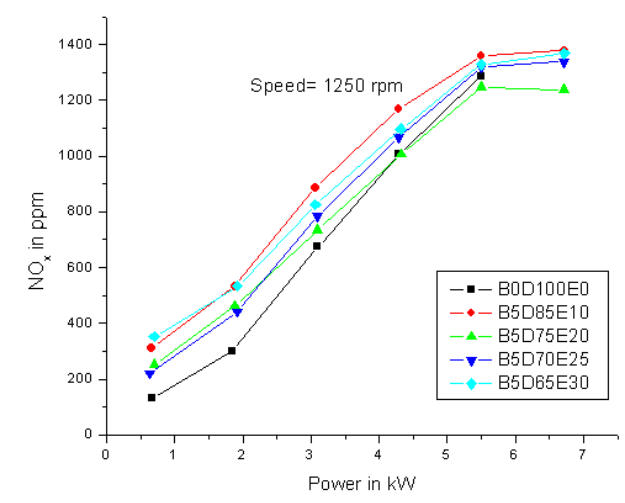

Fig 11. NOx emission for $1250 \mathrm{rpm}$.

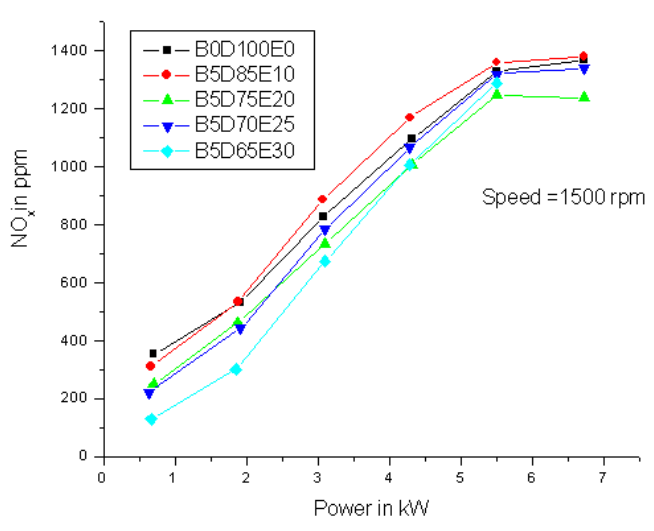

Fig 12. NOx emission for $1500 \mathrm{rpm}$.

The fig: 12 shows, at $1500 \mathrm{rpm}$ when fuelled by B5D70E25, the NOx emissions from the engine are not stable, at different engine loads. There duction was more or less $25 \%$ Similar trend can be seen for that fuelled by B5D65E30.The NOx emissions from the engine were reduced at the low speed when fuelled by blended fuels; but at the high speed, there is not a stable trend for the NOx emissions.

When fuelled by B5D70E25, the NOx emissions from the engine are not stable, at different engine loads, the increases and decreases are between $0.9 \%$ and $5.2 \%$ in absolute value, except at the point of the lowest load - the reduction was $29.1 \%$ Similar trend can be seen for that fuelled by B5D65E30, the NOx emissions from the engine are not stable for different engine loads, the increases and decreases are between $2.8 \%$ and $8.1 \%$ except for the lowest load-the reductions are $31.7 \%$ and $59.0 \%$ respectively. From the results, it can be seen that the NOx emissions from the engine were reduced at the low speed.

\section{Conclusions}

An experimental investigation was conducted on the solubility and physical properties of the blends of ethanol with diesel and the effects of the application of these blends on the ceramic heater surface ignition engine performance parameters and emissions. The tested blends were from $10 \%$ to $30 \%$ of ethanol by volume; and also with $5 \%$ of the additive of formaldehyde. The engine was operated with each blend at different power on which the engine speed of $1250 \mathrm{rpm}$ and $1500 \mathrm{rpm}$. Ethanol cannot be blended with diesel without the assistance of additive such as Formaldehyde. With the blends tested, the blends of $10 \%$, $20 \%, 25 \%$ and $30 \%$ ethanol with diesel were all separated into two layers; when 5\% Formaldehyde were added into the above blends, they were all lasted longer and no less than 10 days without the phase separation problem.

The Experiment showed that the formaldehyde is a good additive for mixing diesel with ethanol, although the price of formaldehyde was higher than that of diesel when the tests were carrying on.

From long term point of view, fossil fuels including diesel will be less and less due to the limited sources; more and more bio fuels will be used gradually as the alternatives to replace the fossil fuels. It might not be economical to use Formaldehyde today but it would be in the future.

The brake specific fuel consumption is slightly increased when higher blends of ethanol are used. The fuel consumptions of the engine fuelled by the blends were higher compared with those fuelled by pure diesel. The more ethanol was added in, the higher fuel consumptions were. The differences were from $5 \%$ to $31 \%$ for different blends at different loads and speed.

The thermal efficiencies of the engine fuelled by the blends were comparable with those fuelled by pure diesel, with some extent increases or decreases at different loads and speeds.

The carbon monoxide (CO) emissions from the engine fuelled by the blends were divided into two parts: when the engine ran above half loads, the $\mathrm{CO}$ emissions form the engine fuelled by the blends were lower than those fuelled by diesel; when the engine ran under half loads, the $\mathrm{CO}$ emissions of blends were higher than those of diesel.

The unburned Hydrocarbon (HC) emissions from the engine fuelled by the blends were all higher when the engine ran at the speed of $1500 \mathrm{rpm}$; but the $\mathrm{HC}$ emissions became less as the loads increased.

The nitrogen oxides (NOx) emissions from the engine were reduced for the blends of B5D75E20, B5D70E25 and $\mathrm{B} 5 \mathrm{D} 65 \mathrm{E} 30$ at $1500 \mathrm{rpm}$. There was not a stable trend for the NOx emissions.

\section{References}

[1] Alan C.Hansen ${ }^{\mathrm{a} .}{ }^{*}$, Qin Zhang ${ }^{\mathrm{a}}$, Peter W.L.Lyne ${ }^{\mathrm{b}}$

[2] ${ }^{a}$ Department of Agricultural and Biological Engineering. University of Illinois 1304 W. Pennsylvania Ave., Urbana, IL 61801. USA. 
[3] b School of Bioresources Engineering and Environmental Hydrology. University of Natal, Private Bag X01, Scottsville 3209, South Africa

[4] Ethanol -diesel fuel blends - a review Bioresource Technology 96 (2005) $277-285$

[5] E.A.Ajav ${ }^{\text {a.* }}$, BachchanSingh ${ }^{\text {b }}$, T.K. Bhattacharya ${ }^{\text {c }}$

[6] a Department of Agricultural Engineering, Faculty of Technology, University of Ibadan, Nigeria

[7] b College of Technology, G.B. Pant University of Agriculture \&Technology,Pantnagar - 263145 (U.P), India

[8] c Department of Farm Machinery and power Engineering ,G.B.Pant University of Agriculture \& Technology, Pantnagar - 263145 (U.P), India

[9] Experimental study of some performance parameters of a constant speed stationary diesel engine using ethanol-diesel blends as fuel. Biomass and Bioenergy 17 (1999) 357-365.

[10] DANIEL NG., National Aeronautics and space Administration, Lewis Research center, Cleveland, Ohio 44135, Temperature measurement of a Miniature Ceramic heater in the presence of an Extended Interfering background radiation sources using a multiwavelength pyrometer.

[11] Chonglin Song a." ${ }^{\text {, }}$ ZhuangZhao, ${ }^{\text {a,b }}$, Gang L.V ${ }^{\mathrm{a}}$, JinouSong, LidongLiu $^{\mathrm{a}}$, Ruifen Zhao ${ }^{\text {a }}$

[12] a State Key Laboratory of Engines, Tianjin University, Tianjin 300072, China

[13] ${ }^{b}$ DongfengChooyang Diesel Engine Co. Ltd. China

[14] Carbonyl compound emissions from a heavy -duty diesel engine fueled with diesel fuel and ethanol -diesel blend. Chemosphere 79 (2010) 1033-1039

[15] Douglas J.Ball and Glenn E.Tripp (Delphi Automotive), Louis S. Socha, AchimHeibel and MedhaKulkarni
(Corning, Inc.), Phillip A. Weber ( South west Research Institute), Douglas G. Linden (ASEC Manufacturing)

[16] A comparison of Emissions and Flow Restriction of Thin wall Ceramic Substrates for Low Emission Vehicles. 19901-0271 Society of Automotive Engineers, Inc.

[17] HwanamKim ${ }^{\mathrm{a}}$, Byungchul Choi ${ }^{\mathrm{a}, \mathrm{b} . *}$

[18] ${ }^{\mathrm{a}}$ Graduate School of Mechanical Engineering, Chonnam National University, Gwangju 500-757, Republic of Korea.

[19] ${ }^{b}$ School of Mechanical Systems Engineering, Chonnam National University, Gwangju 500-757, Republic of Korea

[20] Effect of ethanol-diesel blend fuels on emission and particle size distribution in a common - rail direct injection diesel engine with warm-up catalytic converter. Renewable Energy 33 (2008) 2222-2228

[21] JinchengHuang, ${ }^{\mathrm{a}}$ YaodongWang, ${ }^{\mathrm{a}, \mathrm{b} .{ }^{*},} \quad$ ShuangdingLi ${ }^{\mathrm{a}}$, Anthony P.Roskily,

[22] HongdongYu ${ }^{a}$, HuifenLi ${ }^{a}$

[23] a Mechanical Engineering College, Guangxi University, Nanning 530004, China

[24] ${ }^{b}$ The Sir Joseph Swan Institute for Energy Research, Newcastle University, Newcastle upon Tyne NE 1 7RU, United Kingdom

[25] Experimental Investigation on the performance and emissions of a diesel engine fuelled with ethanol - diesel blends. Applied Thermal Engineering 29(2009) 2484-2490

[26] John B. Heywood, Internal Combustion Engine Fundamentals, McGraw Hill Book Company, New Delhi, 1988.

[27] http//global.kyocera.com/prdct/fc/product/pdf/heaters.pdf 